\title{
Some Remarks on Indicative Conditionals
}

\author{
Barbara Abbott \\ Michigan State University
}

\section{Introduction}

This paper concerns indicative conditionals, such as the English examples in (1):

(1) a. If Lynn was at the meeting, she knows what's going on.

b. If we leave now, we can make the 5:00 show.

c. If it rains tomorrow, we won't have a picnic.

We will look at several theories of indicative conditionals grouped into three categories: those that base its semantics on its logical counterpart (the material conditional); intensional analyses, which bring in alternative possible worlds; and a third subgroup which denies that indicative conditionals express propositions at all. We will also look at some problems for each kind of approach.

\section{The Material Conditional Analysis}

There is a long tradition that associates natural language indicative conditionals with the material conditional of propositional logic. (Indeed, introductory logic texts typically assume this identification.) The semantics of the material conditional is given entirely by its truth table, shown in (2).

\begin{tabular}{|l|l|l|}
\hline$p$ & $q$ & $p \supset q$ \\
\hline $\mathrm{T}$ & $\mathrm{T}$ & $\mathrm{T}$ \\
\hline $\mathrm{T}$ & $\mathrm{F}$ & $\mathrm{F}$ \\
\hline $\mathrm{F}$ & $\mathrm{T}$ & $\mathrm{T}$ \\
\hline $\mathrm{F}$ & $\mathrm{F}$ & $\mathrm{T}$ \\
\hline
\end{tabular}

On this account natural language indicative conditionals express a truth function of their component sentences.

\subsection{Problems for the Material Conditional Approach}

There are several problems for this approach. One stressed by Edgington (1995, 2003) is the following: assigning indicative conditionals the material conditional truth function means failing to distinguish between unequally probable conditionals with equally improbable antecedents, like those in (3) (from Jackson 1979/1991, 115): 
(3) a. If the sun doesn't come up tomorrow it won't matter.

b. If the sun doesn't come up tomorrow it will be the end of the world.

In particular, our confidence that the antecedent of $(3 a)$ is false does not match or lack of confidence that the whole conditional is true.

Another problem arises when conditionals are denied. It is hard to see (4a) as truth-conditionally equivalent to (4b).

(4) a. It's not true that if the sun explodes tomorrow the earth won't be affected.

b. The sun will explode tomorrow and the earth will be affected.

And what's worse is that this analysis would make available a number of proofs of the existence of God. Two are given in (5) and (6): the first from Michael Jubien (personal communication, c. 1975), and the second, less pious, version attributed to W.D. Hart by Edgington (1986, 37, n. 6).

(5) i. If God doesn't exist, then it's not the case that if I'm evil, I'll be punished after I die.

ii. I'm not evil!

$\therefore \quad$ God exists.

(6) i. If God doesn't exist, then it's not the case that if I pray, my prayers will be answered (by Him).

ii. I do not pray

$\therefore$ God exists.

It may be small comfort that we can also prove that God doesn't exist anymore, as in (7), from Horn 1989, 378).

(7) i. It's not the case that if God is dead, everything is permitted.

$\therefore \quad$ God is dead and something is forbidden.

The trouble is that negation of a conditional seems typically to be merely understood either as negating the perceived connection between antecedent and consequent, or (depending on the example) as skipping over the antecedent to negate the consequent directly. (The latter reading, as we shall see below, might be derivable conversationally from the former interpretation.) In any case negation of a conditional seems rarely to be understood as asserting the antecedent and denying the consequent.

\subsection{Jackson's Conventional Implicature}

Jackson (1979/1991, 1987) proposes a modified version of the material conditional analysis, on which indicative conditionals convey, in addition to their truth conditions, a conventional implicature (in the sense of Grice 1975) to the 
effect that the assertion as a whole is robust with respect to the antecedent. The idea is that the speaker signals their confidence that, should the antecedent prove to be true, their utterance as a whole will also be. In effect this robustness gravitates to the consequent, since if the antecedent is true the only way for the whole conditional to be true is for the consequent to be true as well. Although this proposed implicature deals only with confidence in truth values, it would conversationally implicate some knowledge on the part of the speaker, standing behind the robustness.

Jackson's analysis appears to solve Edgington's problem: the conventional implicature associated with (3a) will be very different from that associated with (3b), accounting for the difference between them. However it is not so clear that Jackson's approach can solve the second problem. It appears that in (4), the negation is applying to Jackson's conventional implicature, rather than the truth conditions of the conditional. That would be expected if the negation in (4) were a metalinguistic one (cf. Horn 1985). However there doesn't seem at this point to be any reason to think that this negation must be metalinguistic - that it couldn't be an ordinary sentence negation. And in that case it should be negating truth conditions, which gives us line two of the truth table in (2). (We will return to this issue below, however.)

\section{Possible Worlds (Intensional) Analyses}

We have so far ignored subjunctive conditionals such as those in (8):

a. If Lynn had been at the meeting, she would know what's going on.

b. If we were to leave now, we would be able to make the 5:00 show.

c. If it were to rain tomorrow, we would not have a picnic.

Typically, though not always, conditionals with subjunctive morphology involve antecedents which are presumed to be false of the actual or utterance world. They are usually viewed as intensional, and as involving implicit reference to alternative possible worlds. The idea behind a number of proposals (cf. e.g. Stalnaker 1968, Stalnaker \& Thomason 1970, Lewis 1973) is that there is some kind of ordering, or selection function, on possible worlds in terms of their similarity to the actual world or the world of evaluation. The truth value of sentences like those in (8) depend, in a given world of evaluation, on the truth or falsity of the consequent in the closest world or worlds to the evaluation world where the antecedent is true.

\subsection{Stalnaker's Theory}

Stalnaker (1975) proposed assigning indicative conditionals basically the same semantic interpretation as subjunctive conditionals. He introduced the idea of a CONTEXT SET of worlds, among which the selection function should find its value if possible. The idea is that this context set comprises those worlds which are 
consistent with the common ground - the set of beliefs which the speaker acts as if she assumes are shared between herself and her addressee. The difference between indicative and subjunctive conditionals, then, is that with subjunctive conditionals it is understood that the selection function may need to go outside the context set. "I take it that the subjunctive mood in English...is a conventional device for indicating that presuppositions are being suspended" (Stalnaker 1975, 145). (Stalnaker 1984 discusses the difference between indicative and subjunctive conditionals at much greater length, with a less clear outcome. Cf. also Lycan 2001, who proposes an approach similar to that of Stalnaker 1975.)

\subsection{Digression: Domain Restrictor if-clauses}

Before introducing Kratzer's analysis, we should briefly mention another consideration. David Lewis, who was generally a supporter of the extensional approach to indicative conditionals, pointed out that, at least in some cases, the material conditional analysis of if clauses is definitely not going to work (Lewis 1975). These involve "adverbs of quantification", e.g. always, usually, never, which, Lewis argued, quantify over cases. (9a) is equivalent to (9b), but (10a) and (11a) are not equivalent to (10b) and (11b).

(9) a. If it rains, I always take an umbrella.

b. $\forall$ c [It-rains (c) $\supset$ I-take-umbrella (c)]

(10) a. If it rains, I never take an umbrella.

b. $\forall \mathrm{c} \neg[$ It-rains (c) $\supset$ I-take-umbrella (c)]

(11) a. If it rains, I usually take an umbrella.

b. Most c [It-rains (c) つ I-take-umbrella (c)]

(10b) would be true only if it's always raining, and (11b) is satisfied by any world in which most cases are not rainy ones. In the light of examples like these, Lewis proposed that the if in examples (9a)-(11a) be taken as a meaningless marker of a clause which serves as a restriction on the adverbial quantifier (Lewis 1975, 11). We can represent this as (9c)-(11c), below:

c. $\quad[\forall$ c: It-rains (c)] [I-take-umbrella (c)]

c. $\quad[\forall$ c: It rains in c] $\neg[$ I-take-umbrella (c) $]$

$$
\text { c. [Most c: It-rains (c)] [I-take-umbrella (c)] }
$$

Treating the if clause this way gets the truth conditions right.

(Parenthetical remark: Higginbotham (1985) pointed out another group of troublesome examples, where the if clause seems to serve as part of the restriction on a nominal quantifier. Consider (12a) and (13a) below. Their truth conditions are not given by the formulas in $b:(12 b)$ requires that all students goof off and 
fail, while (13b) would be true wherever non-students outnumber students. Instead, the formulas in $\mathrm{c}$, which match the sentences where the if clauses are replaced by explicit nominal modifiers in $\mathrm{d}$, seem better.

(12) a. No student will succeed if he goofs off. [= von Fintel \& Iatridou 2002, ex. 2.]

b. $\quad[\forall \mathrm{x}$ : student $(\mathrm{x})] \neg[\mathrm{x}$ goofs off $\supset \mathrm{x}$ will succeed $]$

c. $\quad[\forall \mathrm{x}$ : student $(\mathrm{x}) \&$ goofs off $(\mathrm{x})] \neg[\mathrm{x}$ will succeed $]$

d. No student who goofs off will succeed.

(13) a. Most students in this program succeed if they work hard. [= Higginbotham 1985, ex. 23a.]

b. [most $\mathrm{x}$ : student $(\mathrm{x})][\mathrm{x}$ works hard $\supset \mathrm{x}$ succeeds]

c. [most $\mathrm{x}$ : student $(\mathrm{x}) \&$ works hard $(\mathrm{x})]$ [x succeeds]

d. Most students who work hard succeed in this program.

However Dekker 2001, and von Fintel \& Iatridou 2002 have pointed out that this analysis won't work in general. For one thing, we can have this type of if-clause with a proper name, which won't accept restrictive modification, as in (14)

Derek succeeds if he works hard. [= Dekker 2001, ex. 20.]

And even when the modified nominal is quantificational, the relative clauses carry existence presuppositions not shared by the if clauses. The pairs below are not equivalent.

(15) a. Exactly three students succeed if they work hard. [= Dekker 2001, ex. 24.]

b. Exactly three students who work hard succeed.

(16) a. Most, but not all, of the students will succeed if they study hard. [= von Fintel \& Iatridou 2002, ex. 38]

b. Most, but not all, of the students who study hard will succeed.

Von Fintel and Iatridou advocate a revised version of Stalnaker's approach which will solve the problems in (12) and (13). Dekker supports a return to the material conditional within his own brand of dynamic semantics, which he argues can also solve these problems.)

\subsection{Kratzer's Analysis}

Kratzer (1986/1991), following up on earlier work, declared that not only is if a mirage in the explicitly adverbial cases, but also in all other cases as well. Her nice bold statement has been frequently quoted:

The history of the conditional is the story of a syntactic mistake. There is no two-place if...then connective in the logical forms of 
natural languages. If-clauses are devices for restricting the domains of various operators (Kratzer 1986, 11).

We have already seen how this analysis works for the explicitly adverbial cases. Kratzer had proposed that even simple indicatives have implicit modal operators, so that an example like (1a) would be given an analysis as in (17):

$$
\text { [must: Lynn was at the meeting] Lynn knows what's going on }
$$

The function of the if clause is to restrict the domain of the modal operator must. The net result is somewhat similar to the Stalnaker semantics for conditionals (17) is true in a world $\mathrm{w}$ if and only if the consequent clause (Lynn knows what's going on) is true in all those worlds accessible from $w$ where the antecedent (Lynn was at the meeting) is true.

\subsection{Problems for the Intensional Analyses}

3.4.1. Edgington's Objection. Edgington gives the following problem for intensional approaches to indicative conditionals, which she views as decisive: if we assign indicative conditionals truth conditions on which conditionals with false antecedents may sometimes be true and sometimes false, we fail to explain the equivalence of disjunctions of the form $p$ or $q$ with indicative conditionals of the form If not $p$ then $q$, as in (18) (from Stalnaker 1975/1991, 136):

a. Either the butler or the gardener did it.

b. If the butler didn't do it, the gardener did.

On the material conditional analysis (18a) and (18b) are logically. equivalent. (This assumes what nobody disputes, that we equate English either-or with logical disjunction, and English sentence negation with logical negation.) However on the possible worlds analysis (18a) could be true while (18b) is false. (This would be the case if the butler did it, but in the closest world in which he didn't, the gardener didn't do it either.)

Edgington's objection is a general one, and bears similarities to occasional proofs that English indicative conditionals must have the semantics of the material conditional (cf. e.g. Hanson 1991). Of course Edgington does not draw that conclusion; we will return to her view below. In any case, I have given another, somewhat less abstract, problem for the intensional view, which is that it does not adequately distinguish indicative conditionals from subjunctive conditionals.

3.4.2. The Snodgrass Affair. Consider the following situation: We have received a number of letters about the water shortage. Almost all of them were 5 pages or less, and all of those received an answer. One letter (from Byram Snodgrass) was 5 pages plus a few words, and the last letter was 8 pages. We did not reply to the last two letters. The 8-page one was just too long to consider, and Byram Snodgrass is a crank who has been writing incoherent letters to us about 
everything under the sun ever since we took on the post of Water Commissioner. We never answer his letters. Actually this letter of Byram's only went onto the sixth page because he added a PS: "If you answer this letter I'll stop writing to you." That made us stop and think, but in the end we threw his letter in the trash like all his other letters.

Byram called our office to find out whether his letter had been sent a reply. Based on the truth in (19),

$$
\text { Every letter no longer than } 5 \text { pages was answered. }
$$

we said (20):

If your letter was no longer than 5 pages, it was answered.

Our reply was truthful.

There is a sharp contrast between the true indicative conditional in (20) and the corresponding subjunctive conditional in (21), which is not true:

If your letter had been no longer than 5 pages, it would have been answered.

As noted, we never answer letters from Byram Snodgrass. Analyses of subjunctive conditionals like that of Stalnaker 1968 and Lewis 1973 seem to give the right truth conditions for (21). In those analyses, we look at the closest world or worlds where the antecedent of a subjunctive conditional is true, and see whether the consequent is true or not. In any of those nearby possible worlds where Byram's letter was not quite 5 pages long, it still did not receive an answer.

Analyses of indicative conditionals which assign them truth conditions similar to those assigned to subjunctive conditionals, and so only consider situations in which the antecedent is true even if this involves considering nonactual possibilities, cannot distinguish between (20) and (21) and hence cannot be correct. The problem with such analyses is that they do not capture the fact that indicative conditionals are always about the actual world, whether their antecedents are true or false. Subjunctive conditionals, on the other hand, involve consideration of hypothetical situations, which may or may not be actual.

3.4.3. Snodgrass vs. Oswald. The examples in (22) and (23), adapted by Lewis $(1973,3)$ from examples given by Adams $(1970,90)$, are frequently given to illustrate the difference between indicative conditionals and subjunctive conditionals.

If Oswald did not kill Kennedy, then someone else did.

If Oswald had not killed Kennedy, then someone else would have. 
It is quite easy to see that one could hold (22) to be true and (23) to be false. Nevertheless these examples do not make the case I wanted to make. Several factors combine to make them unsuitable. One is that there are two different ways to conceive of the antecedent being true, that is, to conceive of it being the case that Oswald did not kill Kennedy. One is to imagine that the crime was committed, but that Oswald did not do it. The other is to imagine that the crime never took place. When we are considering (22), we are considering the first sort of situation and when we consider (23) we are considering the second. Also, when we consider (22) we consider the actual world (I would say we are forced to consider only the actual world, because this is an indicative conditional), and we can do that because there must always be some small doubt about whether Oswald was the murderer (and for some people, of course, there is a lot of doubt). However there can be no doubt that the crime was committed, so for (23) we consider a quite different possible world in which the crime never took place.

In short, for the Oswald examples there are two different ways to imagine the antecedent being true, one of which could hold in the actual world, and the other of which could not. So analyses like those of Stalnaker, Lycan, and Kratzer can account for the difference between them while still only considering situations in which the antecedent is true - an actual situation for (22) and a hypothetical, nonactual one for (23). For the Snodgrass examples, on the other hand, the antecedent is not ambivalent in this way. Instead, the antecedent of the indicative conditional is false at the actual world, but we still judge the whole conditional to be true. For the subjunctive version, on the other hand, we must consider alternative possible worlds in which the antecedent is true, and there it is false because the consequent is still false. (See Gibbard 1980 for a somewhat similar conclusion. However I would differ with Gibbard's claim that indicative conditionals are 'epistemic'.)

\section{Non-Truth-Conditional Approaches}

We seem to have reached an impasse. There seem to be crushing problems for both the material conditional analysis and the possible worlds type of approach. Indeed, Edgington 2003 argues that no truth conditional approach to indicative conditionals can work. The reason is that any such approach will have to either agree with the truth table in (2), or disagree (and the disagreement will be with the bottom half, since everyone agrees on the top half). The material conditional analysis, of course, agrees with the truth table. However, as noted above, it does not accord with our intuitions about sentences like those in (3), repeated here:

a. If the sun doesn't come up tomorrow it won't matter.

b. If the sun doesn't come up tomorrow it will be the end of the world.

On the other hand the possible worlds approach, which disagrees with the bottom half of the truth table, does not accord with our intuitions about the relation between sentences like (18a) and (18b). Although I've given another problem for 
the possible worlds approach, Edgington's argument would apply more generally to any approach which disagrees with the material conditional analysis.

Edgington's conclusion is that indicative conditionals do not have truth conditions. Let us turn to a couple of alternatives that share the feature of not assigning truth conditions to conditionals.

\subsection{Belnap's Assertability Approach}

In a footnote to his discussion of adverbs of quantification (Lewis 1975, 11n), Lewis pointed out how one could force if to behave properly in the examples in (10) and (11), repeated here:

If it rains, I never take an umbrella.

If it rains, I usually take an umbrella.

The trick is to ignore the bottom half of the material conditional truth table. Lewis noted that Belnap (1970) had sketched such an analysis, one which regards utterances of if-then sentences as conditional assertions of the consequent, rather than assertions of a conditional statement, especially one with the truth conditions of the material conditional. (Lewis called the analysis 'far-fetched', but some pretty down-to-earth types (Belnap cites Quine $(1950,21)$ ) have spoken out in its favor.) Rather than giving truth conditions, Belnap focuses on assertion conditions for conditionals: One version is given in (24):

If $\mathrm{A}$ is true, then what ["If $\mathrm{A}$ then $\mathrm{B}$ "] asserts is what $\mathrm{B}$ asserts. If $\mathrm{A}$ is false, then ["If A then B"] is nonassertive. [ $\approx$ Belnap 1970, ex. 1.]

Omitting details, we can see that this approach will have the effect of allowing a negation, as well as other sentence modifiers, to skip over the antecedent clause and go directly to the consequent. But that resolves the problem with the adverbs of quantification. They will apply only with respect to cases in which the ifclause is true - for (10) and (11), to cases in which it rains. Of those none, or most; must be ones where I take an umbrella, which is the result we want.

As noted, Lewis called this approach 'far-fetched', and apparently thought it cost more than retaining a uniform analysis for if-clauses was worth. (His conclusion was to recognize in effect an ambiguity between if as a marker of adverbial restrictors and if as a sentential connective.) However others have viewed this line as attractive, and Edgington's preferred approach has some of the same features.

\subsection{The 'Suppositional' Theory}

Edgington, following Adams (1965, 1966, 1975), supports a 'suppositional theory', which is similar to Belnap's approach in many respects, but which addresses instead our mental processing of conditionals. (Cf. also Gibbard 1980.) 
The idea, following Ramsey 1929, is that in assessing If $p$ then $q$, we typically do not know whether or not $p$ and whether or not $q$. The frequently quoted statement in (25) is often called 'the Ramsey test':

If two people are arguing 'If $p$, will $q$ ?' and both are in doubt as to $p$, they are adding $p$ hypothetically to their stock of knowledge and arguing on that basis about $q \ldots$. We can say they are fixing their degrees of belief in $q$ given $p$. (Ramsey 1931, 247; cited in Gibbard 1980, 227.)

So, to evaluate the conditional claim we add $p$ to the pool of our beliefs and then consider whether or not, on that supposition, $q$ would be the case. We are in essence comparing the probability of $q$ given $p$ with the probability of not-q given p. Edgington urges us to give up the search for truth conditions for indicative conditional sentences, and instead base our analysis of them on their role in our beliefs, as sketched by Ramsey. In particular, and with respect to the material conditional analysis, she is convinced by the disconnect between our judgement of examples like (3a), which we regard as very improbable, and our judgement of the antecedent, which we judge to be highly probable. On the material conditional analysis these judgements should match.

Where the possible worlds approaches make the troublesome bottom half of the material conditional truth table non-truth functional, these new strategies, in essence, delete it. Edgington notes that "it is compatible with T3 [the suppositional theory] to say that 'if $A, C$ ' is...neither truth nor false if $A$ is false" (Edgington 2003, 387). On Belnap's approach 'if $A, C$ ' would be "nonassertive" in that circumstance.

In the following sections I would like to suggest some problems for these approaches.

\subsection{Problems for the Non-Truth-Conditional Approaches}

4.3.1. Are Probability Judgements to be Trusted? As just noted, in defending the suppositional theory against the truth conditional approaches, Edgington puts great weight on the importance of our judgements of conditional probabilities. This seems to accord well with the fact that typically, when conditionals are uttered, neither speaker nor addressee knows the truth value of either the antecedent or the consequent. (As Edgington remarks, God doesn't have any use for ordinary indicative conditionals (Edgington 2003, 385).) And as the Ramsey test suggests, we do that by judging the probability of the conclusion on the condition that the antecedent holds. As noted above, these judgements can conflict sharply with what our judgements should be given the material conditional analysis.

The suggestion I want to make here is that human judgements about probabilities are not that good, and so maybe should not be taken so seriously as the basis of a semantic analysis. Tversky \& Kahneman (1983) have shown, in a number of experiments, that most people, even doctoral students in Decision 
Science at Stanford University, given the right sort of background story, will judge it more likely that Linda is a feminist bank teller than that she is a bank teller. That is, in effect, they judge (26) to be true.

It is more likely that Linda is a feminist bank teller than that she is a bank teller.

Nevertheless we would not want to reappraise our view of the semantics of words like likely given this very widespread human failing. Instead we should look elsewhere to explain this divergence. By the same token, it might be more profitable to look for another explanation for our judgements about (3a) and its antecedent.

4.3.2. True (and Assertable) Conditionals with False Antecedents. Both the suppositional approach and the assertability approach only consider situations in which the antecedent of a conditional is true, in evaluating the conditional as a whole. But there are at least three kinds of cases in which we do want to consider conditionals with false antecedents. One is the Snodgrass case given above as a counterexample to possible worlds approaches. The suppositional and assertability approaches do not fare any better with example (20) than did the possible worlds views: on the assertability approach (20) was unassertable by us, and on the suppositional approach it lacks a truth value.

A second kind of problematic case is presented by a class of conditionals whose whole purpose in life is to convey the falsity of the antecedent. Assertions like (27)

If that's a real diamond, I'll eat my hat.

invite the addressee to conclude, from the obvious falsity of the consequent, that the antecedent must also be false. Such sentences are very useful for lively denials of somebody else's (explicit or implicit) claims. Both the assertability approach and the supposition theory make such uses inexplicable. In case the antecedent is false, which is the very occasion one wants to use a monkey's uncle sentence, the utterance as a whole could not make an assertion (in Belnap's view), or would not have a truth value (on Edgington's view).

The mechanism involved in (27) is modus tollens (from If $A$ then $C$ and not $C$, we may conclude not $A$ ). This argument form in and of itself is the third kind of case causing problems for both of these theories. Consider the conversation in (28):

(28) A: If Mary is home the lights will be on.

B: The lights aren't on.

On the assertability approach, if we accept B's utterance as true, we must conclude either that A's utterance is false, or that A failed to make an assertion at all. On the suppositional approach, accepting B's utterance means A said 
something false or truth valueless. In neither case does it seem that we can use A's utterance to conclude that Mary is not at home. Yet that seems to be the natural conclusion that we should draw, especially if we have reason to believe that what A said isn't false.

\subsection{Intermediate Conclusions}

Let us pause to consider where we are. We have seen basically three types of approaches to indicative conditionals. The material conditional analysis runs into problems with false-seeming conditionals that have false, or probably false, antecedents, as well as with negated conditionals. However Frank Jackson's conventional implicature gave us some hope that these problems could be gotten around. The possible worlds approaches fail to account for our judgements of logical equivalence between certain conditionals and corresponding disjunctions, and also do not adequately distinguish indicative from subjunctive conditionals. The assertability and supposition approaches do not do well with a variety of true conditionals with false antecedents: Snodgrass type examples, monkey's uncle sentences and other, more ordinary, instances of modus tollens. To me, the material conditional approach is seeming like the best bet, but there is another factor to consider.

\section{Grammatical asymmetry}

The considerations in the previous section were intended to lend support to the idea of reconsidering the material conditional analysis of indicative conditionals. However there is another factor which needs to be taken into account - one which has not received much attention, at least in the philosophical literature. The material conditional analysis stresses the similarity in truth conditions between indicative conditionals and logically equivalent conjunctions and disjunctions. The equivalent forms are given in (29), and illustrative examples in (30).
a. If $\mathrm{A}$ then $\mathrm{C}$.
b. Not $\mathrm{A}$ or $\mathrm{C}$.
c. $\quad \operatorname{Not}(\mathrm{A}$ and not $\mathrm{C})$.

(30) a. If Sue comes to the party then George will too.

b. Either Sue won't come to the party or (she will and) George will too.

c. It won't be that Sue comes to the party and George doesn't.

However there is a grammatical difference between sentences like (30a) and those like (30b) and (30c), which reflects a grammatical difference between if on the one hand, and or and and on the other. ${ }^{1}$ The difference is that or and and are coordinating conjunctions (as we used to say in elementary school grammar classes) while if is subordinating. That means that grammatically, the if clause in 
(14a) is a sentential modifier, rather than a clause of equal grammatical standing to its partner.

Grammatical indications of this subordinate status are not hard to find. If clauses can be moved around - to the other side of their consequents, or embedded within them, as shown in (31).

(31) a. George will come to the party, if Sue does.

b. George, if Sue comes to the party, will also come.

The same cannot be done in the other cases - indeed we don't even speak of either-clauses, or and-clauses.

a. * Or George will come to the party, either Sue won't.

b. * It won't be that and George, Sue comes to the party, doesn't.

This grammatical difference does not exist in the logical correspondents, which are all coordinating connectives in the grammatical sense.

Given the asymmetry in grammatical status between antecedent and consequent of a conditional, we would expect to find a difference in their contribution to truth conditions (assuming for the moment that conditionals have truth conditions). In the typical case with sentence adverbials, it is the adverbial element that is the new assertion in the utterance, the rest of the sentence being presupposed or backgrounded. This is true of the unmarked use of examples like those in (33):

a. Lee repaired the machine with great difficulty.

b. Fred bought the lamp because the old one was broken.

However this is, of course, not true in the case of if-clauses, probably because they tend to give prior or background conditions relative to which the consequent is said to hold. (The terms "antecedent" and "consequent" reflect that fact.) Thus it would not make sense to presuppose the consequent while asserting the antecedent. But that means that the focus will be on the main clause, in the case of a conditional.

There are other facts about indicative conditionals which fall into place once this grammatical asymmetry is recognized. One is the possibility of 'consequent' clauses that are in interrogative or imperative form, as in (34):

(34) a. If Lynn is there, give her this envelope.

b. If Lynn is there, will there be enough spinach?

This latter fact suggests that if-clauses are root modifiers, in some sense. Compare also the frequently noted 'illocutionary' type of examples, as in (35).

If you'd like a beer there are some in the fridge. 
Here it seems clear that the if-clause places a condition on the relevance or utility of the speech act which follows.

This being the case, it in turn suggests an explanation for the frequently noted fact that conditional sentences often do not embed as naturally as conjunctions or disjunctions. Compare the following:

(36) a. Either Kim will stay and Fred will go, or Kim will go and Fred will stay.

b. \# If Kripke was there if Strawson was, then Anscomb was there. [= Gibbard 1980, ex. 35]

c. \# Either if you open box $A$, you'll get ten pounds, or if you open box $B$, you'll get a button. [ex. from Edgington 1995, 283]

We have no trouble processing (36a) but (36b) and (36c) are pretty awkward.

Although the grammatical asymmetry of conditionals might seem to be problematic for the material conditional approach, in fact it may help us to explain one of the problems that the material conditional approach runs into. Consider the problem with negating a conditional. We saw above, in connection with example (4), repeated here,

(4) a. It's not true that if the sun explodes tomorrow the earth won't be affected.

b. The sun will explode tomorrow and the earth will be affected.

that negating a conditional did not seem equivalent to asserting the second line of the truth table for $\supset$. Instead, in this case the negation seems to skip over the antecedent and attach itself to the consequent. However that could be due to facts particular to this and other similar examples, namely, that we know by way of real world knowledge that if the sun were to explode the earth would be affected. If we take a more neutral example, say (37):

It's not true that George will come to the party if Sue does.

We see that the negation can be understood more weakly, as denying a connection between antecedent and consequent. The logical thing to suppose is that the stronger negation is inferred as an R-type implicature (in the sense of Horn 1984).

Recall Frank Jackson's proposal, that robustness of the consequent with respect to the antecedent is a conventional implicature of indicative conditionals. Conventional implicatures do not generally fall within the scope of ordinary sentence negation. (38)

It's not the case that even George can solve the problem.

is most naturally understood as conveying that George can't solve the problem, not that he's the least likely person to be able to solve it. However conventional implicatures may fall within the scope of metalinguistic negation (as may just 
about anything else); conveyed by (38) with stress on even, and a continuation such as

a. ...he's the smartest person in the class!

If we could find a way to argue that the negation of an indicative conditional is necessarily metalinguistic, then we would have an explanation for its effect. But if if clauses are root modifiers, then they should not be easily embeddable under a sentence operator. And note too that denial of a conditional does seem ordinarily to call for more of an explanation of what is intended, just as with metalinguistic negation.

There is another potentially relevant fact here, which is that if the speaker of a negated conditional had intended to convey line 2 of the truth table, it would have been quicker and easier to say that. Negating a conditional as a whole requires the cumbersome It is not so/the case that... locution; whereas asserting $A$ and not- $C$ does not. That means that when they choose the more cumbersome form, they must be wanting to convey something else, and denial of the robustness implicature (if Jackson is correct) would be the natural target.

Are we home free then? Can we say that indicative conditionals express the truth conditions of the material conditional, but that they do it in an asymmetrical way, and that they also contain a conventional implicature to the effect of robustness of the consequent with respect to the antecedent? Well, probably not.

\section{Conventional or Conversational Implicature?}

There seem to be, unfortunately, problems for Jackson's conventional implicature approach. One is that it has the same problems with true and assertable conditionals with false antecedents that the other approaches do. To get around this problem Jackson would have to argue that somehow the robustness implicature is suspended in those cases or (possibly) that it shifts direction (from the negated consequent to the negated antecedent).

But even if there were a way around that problem, there are others that arise specifically for the proposal of a conventional implicature. One is that we are not intuitively in touch with the robustness implicature proposed by Jackson. That's not the case with other examples of conventional implicatures, such as the meanings expressed by even, therefore, and but. In the latter cases we know what the words mean; it's just an issue of where in the total meaning package that bit of meaning goes. Whereas in the case of if there is so corresponding confidence.

A third problem is that, as Edgington (2001) has pointed out, examples where the putative implicature is contradicted do not strike us as possibly true anyway, unlike the case of clear conventional implicatures. So, while Edgington's example (39a) seems true but inappropriate, it's not obvious that the same can be said for (39b). 
(39)

a. Even Gödel understood truth-functional logic.

b. If the Socialists win the next US election, they will eliminate health care coverage completely.

The fact that the antecedent of (39b) is almost certainly false should make us think (39b) itself is almost certainly true, but simply misleading. However that is not the case.

Each of these considerations might lead us to wonder whether Jackson's putative conventional implicature (or something like it) should not be regarded instead as a conversational implicature, as proposed by Grice (1989). The latter seems a priori more plausible: the implicature in question has the kind of meaning conversational implicatures do. It also seems quite parallel to a similar implicature for disjunctions cited by Jackson - namely, that each disjunct is robust with respect to the falsity of the other.

Jackson took the Gricean line pretty crudely as saying simply "assert the stronger", and pointed out a number of cases in which conditionals are weaker (more probable) than, say, the negation of their antecedents, but are still assertable. One example is given in (40) (from Jackson 1979/1991, 113):

If the sun goes out of existence in ten minutes time, the earth will be plunged into darkness in about eighteen minutes time.

But even though the denial of the antecedent is slightly less probable than the conditional as a whole, there are other factors that make it unassertable by itself (namely, the fact that everybody knows it's true), and hence allow for the felicitous assertion of the whole conditional. Another of Jackson's reasons for abandoning the Gricean line is that it puts conditionals on a par with disjunctions; but while it's possible (if infelicitous) to assert $A$ or $B$ on the basis of knowing that $A$ is true, we do not, as we've seen, assert If $A$ then $B$ merely by knowing $A$ is false.

There is not time to pursue Jackson's objections to the Gricean line in detail here, and in any case there is a worse problem that may make the whole issue moot. Edgington, as we have seen, places great emphasis on the role of conditionals in thought. I've tried to suggest that that might not be a good basis for an analysis, but nevertheless it does seem to be true that we reason with them. But that raises the problem that any kind of Gricean explanation for the effects of conditionals beyond their truth conditions would have to apply at the level of belief. But Gricean implicatures arise through rules of conversation, hence do not apply to beliefs. As Edgington says:

The difficulties with the truth-functional conditional cannot be explained away in terms of what is an inappropriate conversational remark. They arise at the level of belief. Believing that John is in the bar does not make it logically impermissible to disbelieve "if he's not in the bar he's in the library" ... Believing that the Queen is not at home, I may without irrationality reject the claim that if she's home, she will be worried about my whereabouts. (Edgington 1995, 245.) 
This challenge remains to be met.

\section{Conclusion}

We have reviewed three kinds of approaches to the semantics (and pragmatics) of indicative conditionals, and found, for each of them, some difficult problems. I hope to have promoted the material conditional approach a bit, especially over its intensional rival, but it is clear that serious problems remain to be dealt with.

\section{Endnotes}

*A portion of section 3.4 of this paper is revised from prior presentations in Ann Arbor, November 2002; in East Lansing, December 2002; in Santa Barbara, February 2003; and at the LSA in Boston, January 2004. I am very grateful to Rich Hall, Larry Hauser, Larry Horn, Michael Jubien, Matt McKeon, and Carol Slater for reading and commenting on drafts of that portion, and to Tony Anderson, Gene Cline, Mutsuko Endo Hudson, Kai von Fintel, Sabine Iatridou, Myles McNally, Jeff Pelletier, and Rich Thomason for discussion following those presentations. I am also grateful to Chris Barker, Delia Graff, Stefan Kaufmann, Barbara Partee, and Paul Portner for comments after the SALT presentation. I regret not having had sufficient time to take into account these comments, and especially the work of Kaufmann (cf. Kaufmann 2001, 2003). In any case none of the people mentioned in this footnote should be held responsible for any faults in the current version of this paper.

${ }^{1}$ Since noticing this myself, I've discovered that Edgington mentions it in a footnote $(1995,288$, n. 51). Note that although Kratzer declared that if-then is not a two-place logical connective, she apparently regarded this semantic fact as being at odds with the surface syntax.

\section{References}

Adams, Ernest. 1965. A logic of conditionals. Inquiry 8, 166-197.

Adams, Ernest. 1970. Subjunctive and indicative conditionals. Foundations of Language 6, 89-94.

Adams, Ernest. 1975. The logic of conditionals. Dordrecht: Reidel.

Anderson, Alan Ross. 1951. A note on subjunctive and counterfactual conditionals. Analysis 11, 35-38.

Barker, Stephen. 1995. Toward a pragmatic theory of 'if'. Philosophical Studies 79, $185-211$.

Barker, Stephen. 1997. Material implication and general indicative conditionals. Philosophical Quarterly 47, 195-211.

Barker, Stephen. 2003. Truth and conventional implicature. Mind 112, 1-33. 
Belnap, Nuel D. 1970. Conditional assertion and restricted quantification. Noûs $4,1-12$.

Bennett, Jonathan. 2003. A philosophical guide to conditionals. Oxford: Clarendon Press.

Dekker, Paul. 2001. On if and only. In R. Hastings, B. Jackson, and Z. Zvolenszky, eds., Semantics and Linguistic Theory (SALT) 11. Ithaca, NY: Cornell University, 114-133.

Edgington, Dorothy. 1986/1991. Do conditionals have truth-conditions? Critica XVIII 52, 3-30. Reprinted in Frank Jackson, ed., Conditionals. Oxford: Oxford University Press, 176-201.

Edgington, Dorothy. 1995. On conditionals. Mind 104, 235-329.

Edgington, Dorothy. 2001. Conditionals. Stanford Encyclopedia of Philosophy. http://plato.stanford.edu/entries/conditionals/.

Edgington, Dorothy. 2003. What if? Questions about conditionals. Mind \& Language 18, 380-401.

von Fintel, Kai \& Sabine Iatridou. 2002. If and when if-clauses can restrict quantifiers. Paper for the Workshop in Philosophy and Linguistics, University of Michigan, November 8-10, 2002.

Gibbard, Allan. 1980. Two recent theories of conditionals. In W.L. Harper, Robert Stalnaker, and G. Pearce, eds., Ifs. Dordrecht: Reidel, 211-247.

Grice, H. Paul. 1975. Logic and conversation. In Peter Cole \& Jerry L. Morgan, eds., Syntax and semantics, vol. 3: Speech acts. New York: Academic Press, 41-58.

Grice, H. Paul. 1989. Studies in the way of words. Cambridge, MA: Harvard University Press.

Hanson, William H. 1991. Indicative conditionals are truth-functional. Mind, 53-72.

Higginbotham, James. 1985. Linguistic theory and Davidson's program in semantics. In Ernest Lepore, ed., Truth and interpretation: Perspectives on the philosophy of Donald Davidson. Oxford: Blackwell, 29-48.

Horn, Laurence R. 1983. Toward a new taxonomy for pragmatic inference: Qbased and R-based implicature. In Deborah Schiffrin, ed., Meaning, form, and use in context: Linguistic applications (GURT '84). Washington: Georgetown University Press, 11-42.

Horn, Laurence R. 1985. Metalinguistic negation and pragmatic ambiguity. Language 61, 121-174.

Horn, Laurence R. 1989. A natural history of negation. Chicago: Chicago University Press.

Jackson, Frank. 1979/1991. On assertion and indicative conditionals. Philosophical Review 88, 565-589. Reprinted in Frank Jackson, ed., Conditionals. Oxford: Oxford University Press, 111-135.

Jackson, Frank. 1987. Conditionals. Oxford: Clarendon Press.

Kaufmann, Stefan. 2001. Probabilities of conditionals. In R. Hastings, B. Jackson and Z Zvolenszky, eds., Proceedings of Semantics and Linguistic Theory (SALT) 11. Ithaca NY: Cornell University, 248-267. 
Kaufmann, Stefan. 2003. Conditional predictions: A probabilistic account. To appear in Linguistics and Philosophy.

Kratzer, Angelika. 1986/1991. Conditionals. In CLS 22:2, 1-15. Reprinted in Arnim von Stechow \& Dieter Wunderlich, eds., Semantics: An international handbook of contemporary research. Berlin: de Gruyter, 651-656.

Lewis, David. 1973. Counterfactuals. Cambridge, MA: Harvard University Press.

Lewis, David. 1975. Adverbs of quantification. In Edward L. Keenan, ed., Formal semantics of natural language. Cambridge: Cambridge University Press, 3-15.

Lycan, William G. 2001. Real conditionals. Oxford: Clarendon Press.

Quine, W.V. 1950 Methods of Logic. Cambridge, MA: Harvard University Press.

Stalnaker, Robert. 1968. A theory of conditionals. In Nicholas Rescher, ed., Studies in logical theory. Oxford: Blackwell, 98-112.

Stalnaker, Robert. 1975/1991. Indicative conditionals. Philosophia 5, 269-286. Reprinted in Frank Jackson, ed., Conditionals. Oxford: Oxford University Press, 136-154.

Stalnaker, Robert. 1984. Inquiry. Cambridge, MA: MIT Press.

Stalnaker, Robert \& Richmond Thomason. 1970. A semantic analysis of conditional logic. Theoria 36, 23-42.

Tversky, Amos \& Daniel Kahneman. 1983. Extensional versus intuitive reasoning: The conjunction fallacy in probability judgment. Psychological Review 90, 293-315. 